\title{
Daily Activity Rating Scale
}

National Cancer Institute

\section{Source}

National Cancer Institute. Daily Activity Rating Scale. NCI Thesaurus. Code C141646.

A scale from 0 to 4 for an individual to rate their perception of their daily activities. 